\title{
Comment les oléoprotéagineux peuvent répondre au défi protéines?
}

Comme le soulignent les analyses issues de l'étude prospective de Terres Inovia, on observe aujourd'hui un rééquilibrage du prix des protéines par rapport au prix de l'huile qui s'explique en grande partie par des besoins croissants émanant des pays émergeants. Dans ce contexte, pour satisfaire ces besoins, la part protéique fournie majoritairement par les tourteaux d'oléagineux devra être complétée par un accroissement de la production de cultures protéagineuses (pois, féverole, lupin, lentille, pois chiche... ). L'article d'Étienne Pilorgé et Frédéric Muel intitulé «Quelles huiles et protéines végétales pour 2030 ? La fraction protéique est-elle l'avenir des oléoprotéagineux? » reprend les résultats de l'étude prospective pour la filière huiles et protéines végétales menée par Terres Inovia. Outre l'amélioration de leurs rendements et de leur régularité, une meilleure valorisation des systèmes de cultures incluant des légumineuses pourrait augmenter globalement la production de protéines : productivité, protéines issus des protéagineux et une teneur en protéines améliorée pour des cultures suivantes (effet azote résiduel).

On constate en France une baisse de la part de marché des tourteaux de soja d'importation (la France importe près de 3,5 millions de tonnes de tourteaux de soja pour l'alimentation animale, majoritairement du Brésil) alors que la demande en protéines prend de l'importance. Cette évolution est due aux sources d'approvisionnements métropolitaines en tourteaux colza et tournesol, contribuant ainsi au changement du ratio valeur huile/valeur protéine mais également au renouveau du soja français. En effet, la culture du soja confirme son redéploiement sur le territoire métropolitain pour la quatrième année consécutive. La récolte a atteint 272000 t en 2015 dont 50000 t consommées en nutrition humaine.

La demande en matière protéiques sera également très forte aux niveaux des pays émergeants (BRICS) et plus particulièrement en Asie. Tous ces éléments incitent à penser que la protéine, malgré son statut de coproduit issu de la transformation des oléagineux, doit compter autant sinon plus que la fraction huile, ce qui pourrait orienter différemment les programmes de sélection et les critères de qualités. L'article de Janitha P.D. Wanasundara et al. présente une revue exhaustive des différentes protéines contenues dans la graine de colza, leur allergénicité ainsi que leurs propriétés techno-fonctionnelles pouvant être mise à profit dans des applications alimentaires et non-alimentaires.

Comme le montre l'article de Morgane Saillard intitulé «Tendance de marché en France sur la présence des protéines végétales dans les produits alimentaires », la protéine est également valorisée au niveau de l'alimentation humaine, avec une utilisation croissante d'ingrédients protéiques végétaux dans les denrées alimentaires : concentrats de pois, isolats de soja, farine de fève ou de lupin, ... En France, ces protéines sont utilisées dans de nombreux produits dans un but nutritionnel ou fonctionnel. L'article de Jean-Michel Chardigny et Stéphane Walrand intitulé «Les protéines végétales pour l'alimentation : des opportunités et des verrous » présente notamment la complémentarité des différentes sources protéiques végétales ainsi que la problématique de l'acceptabilité de ces nouveaux aliments par les consommateurs.

L'aspect environnemental est désormais également pris en compte, dans un contexte de réduction de l'empreinte environnementale des produits de grande consommation. Outre l'utilisation de la fraction protéique comme ingrédient fonctionnel, la graine entière peut être utilisée : c'est le cas des produits au soja, qui ne sont plus destinés exclusivement aux végétariens (comme le précise l'article de SOJAXA intitulé «Les aliments au soja : consommation en France, qualités nutritionnelles et données scientifiques récentes sur la santé»).

Ce dossier d'OCL abordera le potentiel des oléoprotéagineux dans l'apport protéique, les nouveaux process pour extraire valoriser et développer l'utilisation des protéines végétales pour les différentes débouchés existants (ce point est illustré dans l'article de Denis Chereau et ses collaborateurs intitulé «Combination of existing and alternative technologies to promote oilseeds and pulses proteins in food applications »), et enfin des exemples d'applications en France et en Europe de protéines végétales dans les produits proposés au consommateur. 